\title{
Canadian Journal of Fisheries
} Publishing and Aquatic Sciences

The co-evolution of adult body mass and excretion rate between genetically size-divergent brook trout populations

\begin{tabular}{|c|c|}
\hline Journal: & Canadian Journal of Fisheries and Aquatic Sciences \\
\hline Manuscript ID & cjfas-2017-0508.R1 \\
\hline Manuscript Type: & Article \\
\hline Date Submitted by the Author: & 27-Apr-2018 \\
\hline Complete List of Authors: & $\begin{array}{l}\text { Guernon, Stéphanie; Université du Québec à Montréal, Sciences } \\
\text { biologiques } \\
\text { Yates, Matthew; Concordia University, Biology } \\
\text { Fraser, Dylan; Concordia University, Biology; Concordia University } \\
\text { Derry, Alison; Université du Québec à Montréal, Sciences biologiques }\end{array}$ \\
\hline Keyword: & $\begin{array}{l}\text { body size, EVOLUTION < General, EXCRETION < General, salmonid, } \\
\text { ecosystem effect trait }\end{array}$ \\
\hline $\begin{array}{r}\text { Is the invited manuscript for } \\
\text { consideration in a Special } \\
\text { Issue? : }\end{array}$ & Not applicable (regular submission) \\
\hline
\end{tabular}




\title{
The co-evolution of adult body mass and excretion rate
}

\section{between genetically size-divergent brook trout populations}

\author{
Stéphanie Guernon*1, Matthew C. Yates ${ }^{* 2}$, Dylan J. Fraser ${ }^{2,3}$, and Alison M. Derry ${ }^{1,3,4}$ \\ *Both authors contributed equally
}

$1 \quad{ }^{1}$ Départment des sciences biologiques, Université du Québec à Montréal (UQAM),

2 P.O. Box 8888, Succursale Centre-Ville, Montréal, Québec, Canada, H3C 3P8

$3 \quad$ Tel: 514-987-3000 ext. 3496

$4 \quad$ Fax: 514-987-4647

5

$6 \quad{ }^{2}$ Department of Biology, Concordia University

7 Montreal, Quebec, Canada H4B 1R6

8

$9 \quad{ }^{3}$ Quebec Center for Biodiversity Science (QCBS)

$11 \quad{ }^{4}$ Corresponding author: derry.alison@uqam.ca

12

13 Email contacts of other authors:

14 s.guernon@hotmail.com

15 matthew.yates@outlook.com

16 dylan.fraser@concordia.ca

17

18

19 Running title: Genetic/maternal divergence in excretion rates of salmonids

20 Keywords: body size; ecosystem effect trait; evolution; excretion; salmonid 


\section{Abstract}

22 We tested if there was a difference in mass-specific excretion rate between two genetically size-

23 divergent brook trout populations that can be accounted for by genetic/maternal factors. We

24 conducted laboratory-based common garden experimentation using $\mathrm{F}_{1}$ generation fish, with five

25 to seven families per population at two ages ( $0.5 \mathrm{y}$ juveniles and $1.5 \mathrm{y}$ adults). We found that

26 genetic/maternal differences in excretion rate on a per gram basis co-evolve with genetic

27 divergence in adult body mass between the populations. However, this co-evolution has also

28 resulted in no net difference in excretion rate between populations when differences in adult

29 body mass were accounted for. Uncertainty in census estimates and variation in body mass

30 distributions created substantial variation in extrapolated whole-population excretion estimates.

31 No other studies to our knowledge have tested for genetic/maternal divergence in excretion rate

32 between genetically size-divergent fish populations. Genetically-based population divergence in

33 body mass, energy allocation in reproduction, and mass-specific excretion rate in the brook trout

34 was likely a result of selection associated with differences in the availability of overwintering

35 habitat between streams. 


\section{Introduction}

Mass-specific nutrient excretion rate in fishes (nutrients excreted per unit body mass per unit time) can be considered a potential `ecosystem effect trait`: it underlies an organism’s direct

40 or indirect effect on an ecosystem function (Matthews et al. 2011) and it can change the

41 availability of limiting nutrients (nitrogen and phosphorus) at the base of aquatic food webs

42 (Atkinson et al. 2016). Recent data compilations have shown that metabolic variables (e.g. body

43 size and temperature) and certain ecological stoichiometric variables (e.g. trophic guild and

44 vertebrate versus invertebrate classification, but not necessarily N:P ratios) are key for predicting

45 nutrient excretion rates of aquatic invertebrates and vertebrates (Allgeier et al. 2015; Vanni and

46 McIntyre 2016). A positive, concave down allometric relationship between animal body mass

47 and nitrogen excretion rate $\left(\mu \mathrm{g} \mathrm{h}^{-1}\right)$, with a power scaling coefficient of less than one, is well

48 established. Larger-bodied fish and macroinvertebrates have higher absolute excretion rates

49 because of their larger organismal biomass (Allgeier et al. 2015; Vanni and McIntyre 2016);

50 however, on a mass-specific basis (per gram), smaller animals usually outpace larger animals in

51 their rate of excretion (Vanni 2002).

52 For fish, recent research has focused on understanding factors that determine interspecific

53 patterns in excretion rate (Villéger et al. 2012; Moody et al. 2015), and the overall role of

54 excretion in aquatic biogeochemical cycling (reviewed in Atkinson et al. 2016). More recently,

55 there is also growing interest in quantifying intraspecific variation in fish excretion rates and

56 relating these to potential effects on nutrient recycling and trophic state in ecosystems (e.g.,

57 Tuckett et al. 2014; Bassar et al. 2017; El-Sabaawi et al. 2017). For example, the size structure

58 of fish populations can have a strong influence on nutrient cycling in aquatic ecosystems if a

59 population is dominated by smaller individuals with higher mass-specific excretion rates 
60 compared to an equivalent biomass of larger-bodied individuals (Allgeier et al. 2016; Catalano

61 and Schaus 2016). However, despite a growing recognition and debate of the importance of

62 evolution in `ecosystem effect traits` in ecological and ecosystem processes (Schoener 2011), the

63 extent to which genetic/maternal differences can explain intraspecific variation in mass-specific

64 fish excretion rate is relatively unexplored (reviewed in El-Sabaawi 2017; but see El-Sabaawi et

65 al. 2016; Leal et al. 2017).

66 The objective of our study was to investigate intraspecific allometric relationships

67 between body mass and excretion rate among two, isolated fish populations that exhibit

68 genetically-based differences in body size and growth. We tested the following questions: 1) Is

69 there a difference in mass-specific excretion rate between genetically size-divergent populations

70 that can be accounted for by genetic/maternal factors? And, 2) which population potentially

71 contributes more nutrients to the streams in the wild, considering the combined effects of mass-

72 specific excretion rate, population body size structure, and population abundance?

73 Our study focused on two isolated, genetically size-divergent populations of a

74 widespread, socio-economically important salmonid, the brook trout (Salvelinus fontinalis

75 Mitchill 1814). The study populations inhabit freshwater streams at Cape Race, NL, Canada

76 (hereafter abbreviated CR) (Table S1; Fig. S1), where they share a common ancestor from which

77 they diverged during the last glaciation 10000 to 12000 years ago (Danzmann et al. 1998).

78 These streams are relatively pristine, having experienced negligible human influence such as fish

79 stocking and negligible fishing pressure due to the small size of adult trout ( 3”-6” in length;

80 Wood et al. 2014).

81 Brook trout at CR represent a useful system for testing intraspecific allometric

82 relationships with excretion rate because local habitat differences have resulted in genetically- 
83 based phenotypic divergence in body size and juvenile and adult growth rate between

84 populations (Wood et al. 2015; Fraser et al. 2018). Research on CR streams has found that

85 stream depth is an important determinant of fish body size: smaller-bodied fish with earlier age

86 at maturity have higher fitness in shallow streams because they are less limited by deep-water

87 habitat for breeding and overwintering survival (Hutchings 1993; Belmar-Lucero et al. 2012).

88 Among our study populations, trout from Cripple Cove River (hereafter abbreviated CC) grow

89 more quickly and are longer and heavier at maturity than trout from Freshwater River (hereafter

90 abbreviated FW) both in the wild (Hutchings 1990, 1996) and under common conditions in a

91 captive environment (Fraser et al. 2018).

92 We anticipated that excretion rate per gram of biomass would be lower for faster growing

93 CC compared to FW trout at the juvenile stage. The quantity of nutrients in a consumer`s

94 excreted wastes is a balance between nutrient supply in the diet and nutrient demand for growth

95 and reproduction in the body (Elser et al. 2003). CC trout may have a higher nutrient demand for

96 growth compared to FW trout, and nutrient supply was controlled in our study because both CC

97 and FW trout were fed to saturation on the same diet under the same laboratory environmental

98 conditions during rearing. Given that animal body size is generally negatively correlated with

99 excretion rate on a per gram basis (Vanni 2002), we also anticipated that the larger CC fish

100 would have a lower mass-specific excretion rate than FW fish at the adult stage. For our second

101 question, we expected that CC trout would have lower nutrient excretion at the whole population

102 scale compared to FW trout. This was because we expected lower mass-specific excretion rates

103 for the larger CC trout, and because CC population densities are lower compared to FW in the

104 wild (Bernos and Fraser 2016).

105 
We conducted controlled laboratory excretion experiments on captive-reared $\mathrm{F}_{1}$ generation CC $\left(46^{\circ} 38.759^{\prime} \mathrm{N}, 5^{\circ} 06.164^{\prime} \mathrm{W}\right)$ and FW (46 $\left.38.760^{\prime} \mathrm{N}, 53^{\circ} 13.304^{\prime} \mathrm{W}\right)$ brook

109 trout. Parents $\left(\mathrm{F}_{0}\right)$ of the $\mathrm{F}_{1}$-generation individuals used for the experiments were wild-caught.

110 Brook trout are the only species present in FW; in CC, this species co-exists with threespine

111 stickleback (Gasterosteus aculeatus Linnaeus 1758) and American eels (Anguilla rostrata

112 Lesueur 1817) (Hutchings 1990). We measured excretion rates at two age classes (age $0.5 \mathrm{y}$ and

$1131.5 \mathrm{y})$ and modelled the allometric relationship between mass and excretion rate for each

114 population using linear mixed-effects models. Our analyses were focused on differences between

115 the two brook trout populations, and family was included as a random variable in the mixed

116 models. We had 5 to 7 families per population and age category, and $n=3$ replicates per family

117 (Appendix A). With an exception of two families that could not be re-measured for the older 1.5

118 y age class due to mortality, most of the same families were conserved between age categories

119 for comparisons of excretion rate between life stages. We extrapolated individual-level

120 measurements of within-population variation in nitrogen excretion rate to the whole-population

121 level using body-size distributions and census population size $\left(\mathrm{N}_{\mathrm{c}}\right)$ estimates for these

122 populations in their natural stream habitat.

123

124 Fish origin and rearing

125 Brook trout gametes were collected in October 2014 from electrofished CC and FW

126 adults, transported during the night to Montreal QC, and used to generate family crosses (one

127 different female $\times$ one different male) at Concordia University. Methods for fish rearing and

128 maintenance are provided in Appendix A and are also described in Fraser et al. 2018. Two sets 
129 of excretion experiments were conducted with almost identical protocols but different age

130 categories of the same families within each population: i) $0.5 \mathrm{y}$ juvenile fish in summer 2015 and

131 ii) 1.5 y adult fish in summer 2016. The majority (>96\%) of the 2014 cohort of CR brook trout

132 matured in the fall of 2016, consistent with the same age-at-maturation observed in a previous

133 study involving captive trout from CR (Fraser et al. 2018). Sexually-mature individuals were

134 determined from visual inspection of spawning "readiness": a release of sperm for males and an

135 elongated cloaca/soft belly for females with obvious egg bulges.

\section{Excretion rate experiments}

138 For the 2015 experiment involving juveniles, fish had been reared in tanks with primarily 139 recirculated municipal water. Water used in the 2015 experiment was a 50:50 ratio of water from 140 the fish rearing tanks: fresh dechlorinated municipal water to reduce initial quantities of

141 ammonia and ammonium in the incubation water for the experiment. For the 2016 experiment

142 involving adult fish, the water was $100 \%$ fresh dechlorinated municipal water because the water

143 in the larger tanks for adult fish was flow through. The temperature of water was $14.7^{\circ} \mathrm{C}$ for the

1442015 experiment ( $0.5 \mathrm{y}$ juveniles) and $16.8^{\circ} \mathrm{C}$ for the 2016 experiment ( $1.5 \mathrm{y}$ adults).

145 Comparisons for this study were made within age classes, not between age classes, and so this

146 difference in incubation temperature between experiments did not influence the interpretation of

147 our results.

148 Immediately prior to experiments, the fish acclimated for 10 minutes in a $3.1 \mathrm{~L}$

149 acclimation container with oxygen diffusers that contained approximately $1 \mathrm{~L}$ of the same water

150 as in the incubation containers for the experiments. A stress-related spike in ammonium

151 excretion can occur immediately following handling and initial confinement (Whiles et al. 2009). 
152 Therefore, the fish were acclimated for 10 min to reduce stress associated with handling and

153 different water used in the incubation containers versus the tanks. Following 10 min acclimation

154 period, the fish fed for 15 min in the acclimation container on the maximum amount of food

155 pellets that the fish could consume in this period through observation. This was done to minimize

156 differences in the level of feeding satiation between fish at the start of the experiment, which

157 could have influenced excretion rate (Kajimura et al. 2004; Whiles et al. 2009). Differences in

158 feeding satiation may have occurred among individuals in the larger rearing tanks where smaller

159 and larger fish were together. By the end of the 15 minutes, all individuals within each container

160 had stopped feeding, i.e. had stopped taking pellets from the surface of the water in the container,

161 in the water column, or from the floor of the container. After 15 min of feeding, fish for each

162 replicate were transferred into $3.1 \mathrm{~L}$ incubation containers with $565 \mathrm{ml}$ of water for the onset of

163 the experiment. Fish were hidden from exterior movements to reduce handling stress during

164 acclimation and feeding.

165 Our response variable in experiments was excretion rate (nutrients excreted per unit time)

166 in the form of excreted nitrogen (ammonia $\mathrm{NH}_{3}+$ ammonium $\mathrm{NH}_{4}$ ). We followed a modification

167 of the protocol for measuring brook trout nutrient excretion described by Whiles et al. (2009).

168 For the 2015 juvenile experiment, we had n=3 replicates per family, and each replicate contained

169 a group of three 0.5-y fish in a 3.1 L container with 500-565 ml of water. The exception was one

170 family for which we had only two replicates because of a limited availability of individuals

171 (CC15). We included three 0.5-y fish per replicate for this age class because laboratory analytical

172 detection limits were too low to reliably detect excretion from a single individual. For the 2016

173 adult experiment, each family-level replicate contained only one 1.5-y fish per 3.1 L container 
174 with $500-565 \mathrm{ml}$ of water as in 2015; the level of replication was maintained at $\mathrm{n}=3$ within each 175 family.

176 To determine the initial quantity of nitrogen present in the water prior to the experiment

177 and/or associated with fish excretion response to handling, an initial water sample for $\mathrm{NH}_{3}+\mathrm{NH}_{4}$

178 analyses were collected per family at five minutes following the introduction of fish into the

179 incubation container. This reduced the water volume in incubation containers from $565 \mathrm{ml}$ to 500

$180 \mathrm{ml}$. The fish were incubated in the containers for a total of $30 \mathrm{~min}$, at which time $65 \mathrm{ml}$ sample of

181 water was removed for the final measure of $\mathrm{NH}_{3}+\mathrm{NH}_{4}$. Fish were then removed from the

182 incubation container to a larger aquarium to recover. Each individual fish was subsequently

183 weighed to $0.01 \mathrm{~g}$ for the juveniles ( $0.1 \mathrm{~g}$ for adults); each individual fish was photographed

184 along with a reference scale to quantify length using the program ImageJ (Rasband 2011).

185 Standard length (cm) was measured from the tip of the nose to the beginning of the caudal fin.

186 Initial and final $65 \mathrm{~mL}$ water samples were $30-\mu \mathrm{m}$ filtered to remove traces of feces and

187 food, and then refrigerated with a 50:50 solution of incubation sample water: sulfuric acid to

188 preserve the $\mathrm{NH}_{3}+\mathrm{NH}_{4}$ (American Public Health Association et al. 2012). Experiments were

189 conducted on two consecutive days; water samples were sent by courier in coolers to the St.

190 Lawrence Institute of Environmental Sciences (Cornwall, ON) for laboratory analyses of

191 excreted nitrogen (N): $\mathrm{NH}_{3}+\mathrm{NH}_{4}$. Laboratory protocols for $\mathrm{NH}_{3}+\mathrm{NH}_{4}$ analyses were based on

192 the phenate method (4500-NH3 F.) (American Public Health Association et al. 2012) that has

193 been modified with substitution of sodium salicylate for phenol (Verdouw et al. 1978). The

194 detection limits were $0.04 \pm 0.02 \mathrm{mg} \mathrm{NH} 3+\mathrm{NH}_{4} \mathrm{~L}^{-1}$. To calculate the final quantity of excreted

195 nitrogen in incubation water $\left(\mu \mathrm{g} \mathrm{NH} \mathrm{NH}_{3}+\mathrm{NH}_{4} \mathrm{~L}^{-1}\right)$, the initial measure of $\mathrm{NH}_{3}+\mathrm{NH}_{4}$ was 
196 subtracted from the final measure. We calculated excretion rate as the amount of nitrogen

197 excreted per unit time $\left(\mu \mathrm{g} \mathrm{NH} \mathrm{NH}_{3}+\mathrm{NH}_{4} \mathrm{~h}^{-1}\right)$, with an incubation time of $0.5 \mathrm{~h}$.

199 Statistical Analyses

200 Excretion -Excretion rates $\left(\mathrm{Ex}, \mu \mathrm{g}^{*} \mathrm{~h}^{-1}\right)$ are often modelled as scaling non-linearly with

201 body mass $(\mathrm{M}, \mathrm{g})$ according to an exponential function with the form $\mathrm{Ex}=a \mathrm{M}^{\mathrm{b}}(\mathrm{El}-\mathrm{Saabawi}$ et 202 al. 2015). Therefore, for both juveniles and adults, linear models in which excretion rate and 203 body mass were natural-log transformed were compared to models in which the data were left 204 untransformed, by examining adjusted $\mathrm{R}^{2}$ values using $\mathrm{R}$, version 3.3.3 (R Core Team 2017). $\mathrm{R}^{2}$

205 values for adults indicated that excretion rates were better modelled using a simple linear 206 regression rather than with natural-log transformed excretion rates and body mass $\left(\mathrm{R}^{2}=0.733\right.$ vs. 207 0.689, respectively); for juveniles, neither model explained significant variation $\left(\mathrm{R}^{2}=0.045\right.$ and 208 -0.016, respectively). Similarly, generalized additive mixed models (including family as a 209 random effect) with non-linear smoother functions did not significantly improve model fit above 210 simple linear models (Supplementary Material, Table S2, Figure S2), and visual examination of 211 residual QQplots from mixed-effects models (see below) indicated a better fit when data was 212 untransformed (Supplementary Material, Figure S3). Untransformed excretion rate and body 213 mass data were therefore presented herein, but see Supplementary Material, Table S3 for log214 transformed body-mass excretion scaling coefficient estimates.

215 Between-population comparisons of excretion rates from the laboratory experiments were 216 tested using general linear mixed effects models. Excretion rate was modeled with population

217 included as a categorical fixed effect and mean-centered individual mass included as a

218 continuous fixed covariate. Metabolic rates can vary in scaling with mass across age classes in 
219 fish (Norin and Gamperl 2017). In our study, age class covaried strongly with mass, with no

220 overlap between age-groups. As a result, we could not model age-dependent scaling factors by

221 including an age-by-body mass interaction in our mixed models (variance inflation factor (VIF)

222 for interaction term was $>300$ ). The relationship between excretion and mass for juvenile and

223 adult age classes was therefore analyzed separately.

224 Excretion rates estimated for the $0.5 \mathrm{y}$ aged treatments represented the total excretion rate

225 of the three individuals used in each experimental replicate; the total mass of all individuals in a

226 replicate was therefore used. For both juvenile and adult models, all possible interactions

227 between fixed effects were tested. A family-level term was included as a random effect in all

228 models regardless of significance to account for non-independence of measurements across

229 related individuals. A random family-by-mass term was also tested to account for potentially

230 different mass-excretion slope relationships among families. When excretion rate scaled

231 significantly with body mass for an age-class, we compared excretion rates for two scenarios: i)

232 standardizing for size differences across populations and ii) comparing average-sized fish from

233 each population.

234 Specific Growth Rates - Mixed effect models were used to test for population-level

235 differences in mass and growth rates measured on individuals in the laboratory experiments.

236 Individual mass measurements were $\ln$-transformed and used as dependent variables in all

237 models; this assumes a growth rate that is proportional to size and constant over time (i.e.

238 specific growth rate). Population (CC vs. FW) was firstly included as a categorical fixed effect.

239 A family-level term was also included as a random effect in all models regardless of significance

240 to account for the non-independence of measurements across related individuals. Time between

241 the two experimental periods (2015 and 2016) was included as a continuous fixed effect; the 
242 slope of mass across time therefore represented specific growth rate. A population-by-time

243 interaction term was included to represent the effect of population on specific growth rate along

244 with a random effect of family-by-time term to account for repeated mass measurements within

245 families across experimental time periods.

246 Statistical analysis was conducted in R using the nlme (Pinheiro et al. 2017) and Ime4

247 (Bates et al. 2015) packages. Separate variances for each experimental period were initially

248 modelled using the 'varIdent' function in nlme. However, this term did not improve model fit

249 (log-likelihood ratio test (LRT); $\left.\chi_{1}^{2}=0.629, P=0.428\right)$ and was dropped; all subsequent

250 analyses were performed in Ime4. Backwards stepwise model selection was conducted to remove

251 non-significant model terms $(P>0.05)$. Complex random-effects terms were tested first using

252 LRTs for models estimated using restricted maximum likelihood (REML). Fixed effects terms

253 were then tested for models estimated using maximum likelihood (ML); F-tests were used for

254 fixed-effect term testing as implemented in pbkrtest (Halekoh and Højsgaard 2014), which

255 estimates denominator degrees of freedom using the Kenward-Roger approximation (Kenward

256 and Roger 2009). If an interaction term was found to be significant, all lower-order terms were

257 automatically included in the final model. Pairwise contrasts between term levels were

258 conducted using $t$-tests. Final parameter estimates were obtained from models estimated using

259 REML.

260

\section{Extrapolated population-level excretion}

262 Excretion rates estimated from the adult brook trout in laboratory conditions were

263 extrapolated to their natural populations, which included a mixture of size and age classes.

264 Captive-reared fish were, on average, larger than similarly aged wild fish; the body size 
265 distribution of the captive fish, overall, was therefore relatively similar to their (older) wild

266 counterparts (Table 1$)$. Adult census population size $\left(\mathrm{N}_{\mathrm{c}}\right)$ population estimates and mass

267 distributions were previously obtained for CC and FW in both natural populations (see Bernos

268 and Fraser 2016 for methodology). Total absolute population excretion was estimated through

269 simulations based on the natural size distributions observed for each population $\left(\mathrm{CC}_{\mathrm{n}}=204, \mathrm{FW}_{\mathrm{n}}\right.$

270 = 137). To account for uncertainty associated with body size distribution estimates, $n$ random

271 samples (where $n=N_{c}$ ) for each population were drawn from a normal distribution with a mean

272 and standard deviation equal to that of the $\ln$-transformed observed population body-mass

273 distribution. New excretion rate values for these samples were generated from back-transformed

274 mass values using the simulate.Mermod command in Ime4 (with random effects marginalized).

275 The simulated excretion rates were then summed to obtain a total population level excretion rate;

276 this process was repeated 10000 times to generate a mean estimate and 95\% confidence intervals

277 for the total population level excretion rate. To account for error in $\mathrm{N}_{\mathrm{c}}$ estimates, this process was

278 repeated for lower and upper 95\% confidence intervals for $\mathrm{N}_{\mathrm{c}}$ estimates. Stream length and width

279 were also quantified in habitat surveys for both populations, enabling an estimate of total stream

280 area. Simulated whole-population excretion rates were divided by total stream area to obtain an

281 approximate per-area excretion rate estimate - this controlled for differences in density observed

282 across the two populations examined. Populations were considered significantly different when

283 confidence intervals did not overlap.

\section{Results}

286 Excretion rates 
Juveniles (age 0.5y) - Body mass of juvenile brook trout was uncorrelated with mass-

288

289

290

291

292

293

294

295

296

297

298

299

300

301

302

303

304

305

306

307

308

309

specific excretion rate (Table 2, Fig. 1a). Neither the random effect family-by-mass term (LRT;

$\chi_{1}^{2}=>0.001, P=1.00$ ) or the fixed-effect mass term (Table 2) were significant. The best-fit

model describing excretion rates in the two populations included only an intercept term.

Adults (age 1.5y) - The best-fit model describing excretion rates in adult brook trout

included the population and mass terms (Table 2). The random effect family-by-mass term was not significant (LRT; $\chi_{1}^{2}=2.002, P=0.157$ ) suggesting that families did not exhibit different

allometric relationships between mass and excretion rate. Body mass of adult brook trout was positively correlated with excretion rate (Table 2, Fig. 1b). The population-by-body mass interaction was not significant indicating that within the adult age-class, populations exhibited a consistent allometric scaling of absolute excretion rate with body mass (Table 2). Individuals from FW excreted, on average, significantly more than those from CC, when comparing fish of the same body size (Table 2, Fig. 1b; mass-specific excretion rate).

The average adult mass across both populations was $29.6 \mathrm{~g}$. At this size, the smaller FW adults excreted significantly more compared to CC adults on a per gram basis $\left(t_{28.89}=4.273, P<\right.$ 0.001; Fig. 2a). However, excretion rate comparisons between populations must additionally account for between-population average body mass differences; an average sized FW adult (at 26.8 g) did not exhibit significantly different absolute excretion rates relative to an average-sized CC adult (at 32.7 g) $\left(t_{27.05}=1.691, P=0.112\right.$; Fig. $\left.2 b\right)$. While FW adults had greater per-gram excretion rates, CC individuals typically grew much larger, resulting in no difference in absolute excretion rates when comparing an average-sized FW adult to an average-sized CC adult.

\section{Body mass and specific growth rates}


The best-fit model describing growth rates in the two populations over time included the

311 population and time terms (Table 1). At initial measurement, CC trout were larger than FW trout

$312\left(t_{11.6}=2.476, P=0.030\right.$, Fig. 1$)$. However, a lack of significance associated with the population-

313 by-time interaction term (Table 1) indicated that both populations continued to grow at the same 314 proportionate rate $\left(0.897 \%\right.$ day $\left.^{-1} \pm 0.013\right)$ during this experimental period. Consequently, CC

315 trout were similarly proportionately larger than FW trout at the second experimental period as

316 they were during initial measurement. The random effect family-by-time term was not

317 significant (LRT; $\left.\chi_{1}^{2}<0.001, P=0.987\right)$ suggesting that families did not exhibit different SGRs.

\section{Extrapolated population-level excretion}

320 Point-estimates for FW N $\mathrm{N}_{\mathrm{c}}$ varied between 4000 and 6500 individuals; CC $\mathrm{N}_{\mathrm{c}}$ varied

321 between 1500-2400. In the wild, CC fish were over twice as large as FW fish (mean of $16.7 \mathrm{~g}$ vs

$3228.1 \mathrm{~g}$ ). Total sampled stream area was similar between streams (FW at $6537 \mathrm{~m}^{2}$ and CC at 6706

$323 \mathrm{~m}^{2}$ ). $\mathrm{N}_{\mathrm{c}}$ estimate availability was incomplete for the sampled populations in some years - only

324 CC N $\mathrm{N}_{\mathrm{c}}$ estimates were available in 2010 and 2012 and only FW estimates are available in 2014.

325 For years in which $\mathrm{N}_{\mathrm{c}}$ estimates were available for both populations (2011 and 2013), total

326 population and per- $\mathrm{m}^{2}$ excretion estimate confidence intervals did not overlap, and FW exhibited

327 significantly greater total absolute excretion rates relative to CC (e.g. approximately a 2-fold and

328 4-fold higher per-m² N excretion in FW in 2011 and 2013, respectively) (Fig. 3; Supplementary

329 Material: Table S4).

330

331 Discussion

332 Mass-specific and absolute excretion rates 
Our study is among the first to provide evidence of genetic/maternal differences in mass-

334 specific excretion rate between fish populations (Fig. 1b; Fig. 2a). In line with our first

335 prediction, the smaller-sized FW adults had a higher gram-specific excretion rate across all body

336 masses compared to the larger adult CC fish under common environmental conditions (different

337 intercepts, Fig. 1b; Fig 2a). Smaller fish are generally known to have higher excretion rates than

338 larger fish on a per gram basis (Vanni 2002); we found evidence that, regardless of size, fish

339 from FW consistently excreted more nitrogen than CC fish. However, since the larger (on

340 average) CC adults excreted more total nitrogen on an absolute basis compared to the smaller

341 FW adults that excreted more nitrogen on a per gram basis, there was no difference in average

342 absolute individual excretion rates between the two populations (Fig. 2b). While

343 genetic/maternal differences in excretion rate on a per gram basis co-evolved with genetic

344 divergence in body mass between these trout populations, this co-evolution has also resulted in

345 no net difference in average absolute individual excretion rate between populations when

346 average population adult body masses were taken into consideration. Other research on

347 population-level differences in excretion rate in fish has not differentiated between

348 environmental acclimation and genetic/maternal sources of intraspecific variation in excretion

349 rates (e.g., Trinidadian guppies: Bassar et al. 2015; El Sabaawbi et al. 2015b; Bassar et al. 2017;

350 three-spine stickleback: El Sabaawi et al. 2016). The only research that we are aware of to date

351 that has addressed a genetic basis for population divergence in nutrient excretion was done on

352 three-spine stickleback with divergent population morphology in plating armour and ecological

353 stoichiometry (Leal et al. 2017). Our research provides a unique contribution because no other

354 studies, to our knowledge, have tested for genetic/maternal divergence in mass-specific and

355 absolute excretion rate between genetically size-divergent fish populations. 
The body mass of adult brook trout individuals positively correlated with mass-specific

357 excretion rate, as predicted by metabolic theory for interspecific differences across animal taxa

358 (Allgeier et al. 2015; Vanni and McIntyre 2016). There was no difference in allometric scaling of

359 mass-specific excretion rate with adult body mass between the two populations (similar slopes,

360 Fig. 1b), which was also consistent with this literature. No relationship was detected between

361 body mass and mass-specific excretion rate in the juvenile 0.5 y fish (Fig. 1a). However, this

362 finding for the juvenile fish may be related to a low range in small body sizes combined with

363 analytical limits for nitrogen detection in the lab $\left(0.04 \pm 0.02 \mathrm{mg} \mathrm{NH}_{3}+\mathrm{NH}_{4} \mathrm{~L}^{-1}\right)$.

365 Body mass and specific growth rates

366 The body size differences that we observed between the study populations under common

367 environmental conditions concur with previous research. CC adult trout were longer and heavier

368 compared to FW trout in the wild (Hutchings 1990, 1993, 1996; Fraser et al. 2018) and under

369 common environmental conditions (Fraser et al. 2018; this study). It is possible that CC and FW

370 fish have similar efficiency in converting food to biomass, but they differ in how this biomass is

371 allocated to growth and reproduction, as has been found in guppies (Reznick 1983). For instance,

372 CC produce more eggs per female and have slightly smaller alevins (Hutchings 1996), yet in the

373 wild reproduce at one year later and at a larger female body size compared to FW (Hutchings

374 1990, 1993, 1996).

375 Our common-garden experiment could not entirely control for maternal effects from the

376 wild in mass-specific excretion rate since we examined $F_{1}$ rather than $F_{2}$ generation fish.

377 However, it is also possible that had we reared the trout to the $F_{2}$ generation, this could have

378 imparted maternal effects in excretion rate more related to rearing conditions in a tank than 
379 maternal effects from the wild. This aside, in the wild, FW females invest proportionally more in

380 their offspring in terms of egg size and number (Hutchings 1990) and alevin size (Wood et al.

381 2015), and so we might have expected that a strong maternal effect would have resulted in larger

382 FW juveniles than CC juveniles at $0.5 \mathrm{y}$. Instead, at initial measurement, CC trout were larger

383 than FW trout and there was no evidence for a between-population difference in specific growth

384 rate (Table 1): both populations continued to grow at the same proportionate rate from juvenile

385 to adults during the experimental period examined. Genetic divergence in body size, combined

386 with a comparison of lab-reared $\mathrm{F}_{1}$ offspring under common environmental conditions, supports

387 a genetic component to the phenotypic difference in mass-specific excretion rate between the

388 trout populations (Wood et al. 2015; Fraser et al. 2018). By using controlled laboratory

389 experiments with $\mathrm{F}_{1}$ generation fish that minimized environmental effects that could have

390 influenced nitrogen excretion rates, such as water temperature, dietary quality, and water source,

391 our study provides evidence to support a genetic basis for differences in body mass and in per

392 gram excretion rate between the brook trout populations.

394 Extrapolated population-level excretion

395 Consistent with our second prediction, whole population-level estimates of absolute fish

396 nitrogen contributions to streams through total excretion were lower in CC compared to FW

397 (Fig. 3). These estimates were based on extrapolations from allometric relationships measured

398 between average adult trout body mass and absolute excretion rate in the lab (Fig. 2b), and they

399 took into consideration stream population abundance and body size distribution as well as stream

400 area. We attributed this finding to similar average individual adult excretion rates between

401 populations (Fig. 2b) but lower population abundances in CC compared to FW (Wood et al. 
402 2014; Bernos and Fraser 2016). The population-level excretion estimates incorporated several 403 sources of error - variability associated with body size distribution estimates in the wild, family404 level variability in excretion rate, and uncertainty in $\mathrm{N}_{\mathrm{c}}$ estimates, all of which were significant 405 sources of error in simulated data (see Fig. 3). Our preliminary findings are suggestive of the 406 potential importance for stream population body size distributions in relation to allometric 407 relationships in determining total absolute excretion at the whole population-level, which would 408 need to be confirmed with excretion studies conducted in the wild. In support of these findings, 409 other research using field-measured excretion rates has also found that population density and 410 biomass can have a stronger contribution to population-level excretion relative to organismal 411 attributes such as body size and growth (mammals: Habeck and Meehan 2008; fish: El-Sabaawi 412 et al. 2015; Tuckett et al. 2014).

\section{Caveats}

415 It is unknown if the genetic/maternal basis for the difference in mass-specific excretion

416 rate between brook trout populations that we observed plays an important role in nature. In

417 nature, local environmental conditions can differ between populations and can influence

418 population excretion rates in aquatic ecosystems. For example, temperature effects on

419 metabolism and body size have been identified as the primary drivers of excretion rate for many

420 animal groups (Allgeier et al. 2015; Vanni and McIntyre 2016). Warmer temperatures within the

421 thermal optima of species can increase metabolic rates and excretion rates of aquatic organisms

422 (Vanni and McIntyre 2016). However, temperature unlikely has a strong effect on between-

423 population differences in excretion rates in our study’s streams. For example, average summer

424 (main growth season) temperatures in CC and FW rivers were $14.9^{\circ} \mathrm{C}$ and $14.7^{\circ} \mathrm{C}$, respectively 
425 (four-year average: 2012-2015; M.C. Yates, Concordia University, unpublished data; $17^{\circ} \mathrm{C}$ in

$426 \mathrm{CC}$ and $16.9^{\circ} \mathrm{C}$ in $\mathrm{FW}$ in 2015 , Table S1). Body mass differences between trout populations,

427 rather than temperature differences between the streams, are likely more important for

428 determining mass-specific and absolute excretion rates of brook trout in CC and FW streams.

429 Other factors that can potentially influence fish excretion rates are diet (Moody et al.

430 2015) and body tissue stoichiometry (McIntyre and Flecker 2010). In our experiments, carry-

431 over acclimation effects from source river conditions were reduced by controlling for dietary

432 quality during rearing conditions and by using $F_{1}$ fish that were reared exclusively in the

433 laboratory. However, in nature, there is often variation between streams in terms of the quantity

434 and quality of dietary resources for brook trout: for instance, there is higher invertebrate biomass

435 in CC compared to FW (Hutchings 1993). The body tissue stoichiometry of brook trout from

436 these populations has not been measured, and it is possible that variation in N:P ratios of tissue

437 content between populations and families within each of the populations could influence both

438 phosphorus and nitrogen excretion rates in the wild because of local differences in resource

439 quantity and quality. However, extensive data syntheses have indicated that tissue N:P is a

440 relatively weak predictor of animal excretion rate compared to metabolic predictors such as body

441 mass and water temperature for generalized carnivores such as salmonids (Allgeier et al. 2015;

442 Vanni and McIntyre 2016).

\section{$444 \quad$ Implications}

445 Genetically-based population divergence in body mass and mass-specific excretion rate in

446 brook trout was most likely a result of ongoing selection associated with differences in the

447 availability of overwintering habitat between CC and FW streams, as has been found for other 
448 streams at CR (Hutchings 1993; Belmar-Lucero et al. 2012). Energy allocation in reproduction

449 rather than growth, as is the case for FW, can be an adaptive response to high post-reproductive

450 mortality in the females (Reznick 1983; Hutchings 1993) that may result from reduced

451 overwintering habitat availability in FW compared to CC, although this needs to be confirmed

452 for these specific streams. The larger, faster-growing CC trout that reach reproductive maturity

453 later may have a higher nutrient demand for growth compared to the smaller FW trout that

454 reproduce commonly 1 y earlier (Hutchings 1993). Nutrient supply was controlled in our study

455 because both CC and FW trout were fed to saturation on the same diet under the same laboratory

456 environmental conditions during rearing. Since the quantity of nutrients in a consumer`s excreted

457 wastes is a balance between nutrient supply in the diet and nutrient demand for growth and

458 reproduction in the body (Elser et al. 2003), lower metabolic rates could have resulted in a higher

459 mass-specific excretion rate in FW trout because of a lower quantity of nitrogen assimilated from

460 the food for growth. In FW trout, this could have enabled the re-allocation of energy to

461 reproduction in terms of earlier reproductive maturity at a smaller adult body size and production

462 of larger eggs (Hutchings 1990) and larger alevins (Wood et al. 2015). The consequences of

463 intraspecific variation on basal metabolic rate, which is related with an organism`s ability for

464 maintenance, growth, and reproduction, on fitness is an emerging area of research (Burton et al.

465 2011; Pettersen et al. 2016). There is evidence that basal metabolic rate is often heritable

466 (Pettersen et al. 2018), and our findings on excretion rates between genetically size-divergent

467 brook trout support this view. Future research on brook trout at Cape Race NL could be used to

468 inform an emerging field of research on the ecological and evolutionary consequences of basal

469 metabolic rate on body size, reproductive investment, and organismal fitness, as well as on

470 ecosystem processes related with nutrient cycling. 
472 ecosystems (Scott and Crossman 1973) and high intraspecific trait variation (Fraser et al. 2011).

473 There is a need to include salmonids in intraspecific studies of `ecosystem effect traits`because

474 of the potential for these fish to impact the nutrient cycling of aquatic ecosystems through

475 migratory behaviour (Wheeler et al. 2015), their presence as exotic species in certain ecosystems

476 (Tronstad et al. 2015; Alexiades et al. 2017), or through differences in population size structure

477 that may be a result of natural selection, as is the case in our study, or as a result of size-selective

478 harvesting because of their socio-economic importance (Fraser 2013; Kendall et al. 2014).

479 Salmonids such as brook trout are often size-selectively harvested, and can undergo

480 evolution of smaller body sizes and earlier maturation ages over time (Palkovacs 2011; Fraser

481 2013; Kendall et al. 2014). In our study of brook trout, which are not size-selectively harvested

482 in the Cape Race NL system, we found evidence to support genetically-based co-evolution

483 between body mass and mass-specific excretion rate in the adult fish. It is possible that fisheries-

484 induced evolution in other brook trout populations that are size-selectively harvested could

485 potentially result in increased mass-specific excretion rates. Indeed, other research has found that

486 harvest-induced size structure of fish populations can induce changes in lake nutrient cycling

487 (gizzard shad: Catalano and Schaus 2016) and nutrient contributions to coral reefs (many fish

488 species: Allgeier et al. 2016). However, also consistent with other research (El-Sabaawi et al.

489 2015; Tuckett et al. 2014), our preliminary findings for extrapolated total population absolute

490 excretion suggest that total population densities and biomass may be more important than

491 allometry and population body size structure in determining total fish population nutrient

492 contributions through excretion to aquatic ecosystems. 
Future work in the CR system could measure the influence of genetically-based

494 population divergence in brook trout excretion on nutrient contributions at the whole-ecosystem

495 level. To do this, we would need to consider the water chemistry and nutrient export in the

496 streams, excretion rates of $\mathrm{F}_{0}$ fish, as well as nutrient cycling within the food web. This approach

497 could contribute to a deeper understanding of the extent of reciprocal interactions between

498 evolution and ecology ('eco-evolutionary interactions`) in nature (Schoener 2011).

499

500

\section{Acknowledgements}

502 This research was funded by a seed grant from the Quebec Center for Biodiversity Science to 503 AMD and DJF and supported by an NSERC Discovery Grant to DJF. MCY was funded from an 504 NSERC PGS-D scholarship. All applicable institutional and/or national guidelines for the care 505 and use of animals were followed (Concordia University permit \#: AREC 30000249). 


\section{References}

507 Alexiades, A.V., Flecker, A.S., and Kraft, C.E. 2017. Non-native fish stocking alters stream 508 ecosystem nutrient dynamics. Ecol. Appl. 27(3): 956-965. doi: 10.1002/eap.1498.

509 Allen, A.P., and Gillooly, J.F. 2009. Towards an integration of ecological stoichiometry and the 510 metabolic theory of ecology to better understand nutrient cycling. Ecol. Lett. 12(5): 369-384. 511 doi: 10.1111/j.1461-0248.2009.01302.x.

512 Allgeier, J.E., Wenger, S.J., Rosemond, A.D., Schindler, D.E., and Layman, C.A. 2015.

513 Metabolic theory and taxonomic identity predict nutrient recycling in a diverse food web.

$514 \quad$ Proc. Natl. Acad. Sci. U.S.A. 112(20): E2640-E2647. doi: 10.1073/pnas.1420819112.

515 Allgeier, J.E., Valdivia, A., Cox, C., and Layman, C.A. 2016. Fishing down nutrients on coral $516 \quad$ reefs. Nat. Commun. 7: 12461. doi: 10.1038/ncomms12461

517 American Public Health Association, American Water Works Association, and Water 518 Environment Federation. 2012. 4500- NH3 - Nitrogen (Ammonia) F. Phenate Method. In 519 Standard methods for the examination of water and wastewater. Edited by American Public 520 Health Association, American Water Works Association and Water Environment 521 Federation, Washington, D.C. pp. 115-116.

522 Atkinson, C.L., Capps, K.A., Rugenski, A.T., and Vanni, M.J. 2016. Consumer-driven nutrient 523 dynamics in freshwater ecosystems: from individuals to ecosystems. Biol. Rev. 92(4): 2003524 2023. doi: 10.1111/brv.12318.

525 Bassar, R. D., T. Heatherly, M. C. Marshall, S. A. Thomas, A. S. Flecker, and D. N. Reznick. 526 2015. Population size-structure-dependent fitness and ecosystem consequences in 527 Trinidadian guppies. J. Anim. Ecol. 84(4): 955-968. doi: 10.1111/1365-2656.12353 
528 Bassar, R. D., B. L. Bryan, M. C. Marshall, C. M. Pringle, D. N. Reznick, and J. Travis. 2017. 529 Local adaptation of fish consumers alters primary production through changes in algal 530 community composition and diversity. Oikos 126(4): 594-603. doi: 10.1111/oik.03965

531 Bates, D., Maechler, M., Bolker, B., and Walker, S. 2015. Fitting Linear Mixed-Effects Models $532 \quad$ Using lme4. J. Stat. Softw. 67: 1-48. doi: 10.18637/jss.v067.i01.

533 Belmar-Lucero, S., Wood, J.L.A., Scott, S., Harbicht, A.B., Hutchings, J.A., and Fraser, D.J. 534 2012. Concurrent habitat and life history influences on effective/census population size 535 ratios in stream-dwelling trout. Ecol. Evol. 2(3): 562-573. doi: 10.1002/ece3.196.

536 Bernos, T.A., and Fraser, D.J. 2016. Spatiotemporal relationship between adult census size and 537 genetic population size across a wide population size gradient. Mol. Ecol. 25(18): 4472538 4487. doi: 10.1111/mec.13790.

539 Burton, T., Killen, S.S., Armstrong, J.D., and Metcalfe, N.B. 2011. What causes intraspecific 540 variation in resting metabolic rate and what are its ecological consequences? Proc. R. Soc. B. 541278 (1724): 3465-3473. doi: 10.1098/rspb.2011.1778

542 Catalano, M.J., and Schaus, M.H. 2016. Harvest-induced size structure shifts alter nutrient release 543 by a population of omnivorous fish. Trans. Am. Fish. Soc. 145(3): 637-648. doi: 544

545 Danzmann, R.G., Morgan, R.P., Jones, M.W., Bernatchez, L., and Ihssen, P.E. 1998. A major 546 sextet of mitochondrial DNA phylogenetic assemblages extant in eastern North American 547 brook trout (Salvelinus fontinalis): distribution and postglacial dispersal patterns. Can. J. 548 Zool. 76(7): 1300-1318. doi: 10.1139/z98-056. consequences of evolution. Copeia 105(3): 558-568. doi: 10.1643/OT-16-530 
551 El-Sabaawi, R.W., Marshall, M.C., Bassar, R.D., López-Sepulcre, A., Palkovacs, E.P., and

552 Dalton, C. 2015. Assessing the effects of guppy life history evolution on nutrient recycling:

553 from experiments to the field. Freshwater Biol. 60(3): 590-601. doi: 10.1111/fwb.12507.

554 El-Sabaawi, R.W., Warbanski, M.L., Rudman, S.M., Hovel, R., and Matthews, B. 2016.

555 Investment in boney defensive traits alters organismal stoichiometry and excretion in fish.

556 Oecologia 181(4): 1209-1220. doi: 10.1007/s00442-016-3599-0.

557 Elser, J.J., Acharya, K., Kyle, M., Cotner, J., Makino, W., Markow, T., Watts, T., Hobbie, S.,

558 Fagan, W., Schade, J., Hood, J., and Sterner, R.W. 2003. Growth rate-stoichiometry

559 couplings in diverse biota. Ecol. Lett. 6(10): 936-943. doi: 10.1046/j.1461-

$560 \quad$ 0248.2003.00518.x.

561 Fraser, D.J. 2013. The emerging synthesis of evolution with ecology in fisheries science. Can. J.

562 Fish. Aquat. Sci. 70(9): 1417-1428. doi: 10.1139/cjfas-2013-0171.

563 Fraser, D. J., Weir, L. K., Bernatchez, L., Hansen, M. M. and Taylor, E. B. 2011. Extent and

564 scale of local adaptation in salmonid fishes: review and meta-analysis. Heredity 106(3):

565 404-420. doi: 10.1038/hdy.2010.167.

566 Fraser, D.J., Walker, L., Yates, M.C., Marin, K., Wood, J.L.A., Zastavniouk, C. and Bernos, T.

567 2018. Population correlates of rapid captive-induced maladaptation in a wild fish. Evol.

568 Appl. In press.

569 Habeck, C.W., and Meehan, T.D. 2008. Mass invariance of population nitrogen flux by

570 terrestrial mammalian herbivores: an extension of the energetic equivalence rule. Ecol. Lett.

571 11(9): 898-903. doi: 10.1111/j.1461-0248.2008.01198.x. 
572 Halekoh, U., and Højsgaard, S. 2014. A Kenward-Roger Approximation and Parametric Boot573 strap Methods for Tests in Linear Mixed Models - The R Package pbkrtest. J. Stat. Softw. $574 \quad$ 59: 1-30. doi: $10.18637 /$ jss.v059.i09.

575 Hutchings, J.A. 1990. The evolutionary significance of life history divergence among brook 576 trout, Salvelinus fontinalis, populations. Ph. D. thesis, Department of Biology, Memorial $577 \quad$ University of Newfoundland, St. John's, N. L.

578 Hutchings, J.A. 1993. Adaptive Life Histories Effected by Age-Specific Survival and Growth 579 Rate. Ecology 74(3): 673-684. doi: 10.2307/1940795.

580 Hutchings, J.A. 1996. Adaptive phenotypic plasticity in brook trout, Salvelinus fontinalis, life 581 histories. Ecoscience 3(1): 25-32. doi: 10.1080/11956860.1996.11682311.

582 Kajimura, M., Croke, S.J., Glover, C.N., and Wood, C.M. 2004. Dogmas and controversies in 583 the handling of nitrogenous wastes: The effect of feeding and fasting on the excretion of ammonia, urea and other nitrogenous waste products in rainbow trout. J. Exp. Biol. 207(12): 1993-2002. doi: 10.1242/jeb.00901.

586 Kendall, N.W., Dieckmann, U., Heino, M., Punt, A.E., and Quinn, T.P. 2014. Evolution of age 587 and length at maturation of Alaskan salmon under size-selective harvest. Evol. Appl. 7(2): 313-322. doi: 10.1111/eva.12123.

Kenward, M.G., and Roger, J.H. 2009. An Improved Approximation to the Precision of Fixed 590 Effects from Restricted Maximum Likelihood. Comput. Stat. Data Anal. 53: 2583-2595. 591 doi: 10.1016/j.csda.2008.12.013. 
592 Leal, M.C., Best, R.J., Durston, D., El-Sabaawi, R.W., and Matthews, B. 2017. Stoichiometric 593 traits of stickleback: Effects of genetic background, rearing environment, and ontogeny. $594 \quad$ Ecol. Evol. 7(8): 2617-2625. doi: 10.1002/ece3.2802.

595 Matthews, B., Narwani, A., Hausch, S., Nonaka, E., Peter, H., Yamamichi, M., Sullam, K.E., 596 Bird, K.C., Thomas, M.K., Hanley, T.C., and Turner, C.B. 2011. Toward an integration of 597 evolutionary biology and ecosystem science. Ecol. Lett. 14(7): 690-701. doi: 10.1111/j.1461-0248.2011.01627.x.

McIntyre, P.B., and Flecker, A.S. 2010. Ecological stoichiometry as an integrative framework in stream fish ecology. Am. Fish. Soc. Symp. 73: 539-558. doi: 10.1073/pnas.0608148104.

McIntyre, P.B., Flecker, A.S., Vanni, M.J., Hood, J.M., Taylor, B.W., and Thomas, S.A. 2008. Fish distributions and nutrient cycling in streams: can fish create biogeochemical hotspots? Ecology 89(8): 2335-2346. doi: 10.1890/07-1552.1.

Moody, E.K., Corman, J.R., Elser, J.J., and Sabo, J.L. 2015. Diet composition affects the rate and N:P ratio of fish excretion. Freshwater Biol. 60(3): 456-465. doi: 10.1111/fwb.12500. 388. doi: 10.1111/1365-2435.12996

Palkovacs, E.P. 2011. The overfishing debate: an eco-evolutionary perspective. Trends Ecol.

610 Evol. 26(12): 616-617. doi: 10.1016/j.tree.2011.08.004.

611 Pettersen, A.K., White, C.R., and Marshall, D.J. 2016. Metabolic rate covaries with fitness and 612 the pace of life in the field. Proc. R. Soc. B. 283(1831): 20160323. doi: 10.1098/rspb.2016.0323.

614 Pettersen, A.K., Marshall, D.J., and White, C.R. 2018. Understanding variation in metabolic rate. 

J. Evol. Biol. 221(1) doi: 10.1242/jeb.166876

616 Pinheiro, J., Bates, D., DebRoy, S., Sarkar, D., and R Core Team. 2017. nlme: Linear and 617 Nonlinear Mixed Effects Models. R package version 3.1-131, https://CRAN.R618 project.org/package=nlme.

619 R Core Team. 2017. R: A language and environment for statistical computing. Available from 620 http://www.R-project.org/.

621 Rasband, W.S. 2011. ImageJ. Available from https://imagej.nih.gov/ij/.

622 Reznick, D. 1983. The Structure of Guppy Life Histories: The Tradeoff between Growth and 623 Reproduction. Ecology 64(4): 862-873. doi: 10.2307/1937209.

624 Schoener, T.W. 2011. The newest synthesis: understanding the interplay of evolutionary and 625 ecological dynamics. Science 331(6016): 426-429. doi: 10.1126/science.1193954.

626 Scott, W.B., and Crossman, E.J. 1973. Freshwater Fishes of Canada. Bull. Fish. Res. Board Can. $627 \quad$ No. 184.

628 Tronstad, L. M., Hall Jr., R. O., and Koel, T. M. 2015. Introduced lake trout alter nitrogen 629 cycling beyond Yellowstone Lake. Ecosphere 6(11): 224. doi: 10.1890/ES14-00544.1.

630 Tuckett, Q.M., Simon, K.S., Saros, J.E., Coghlan Jr., S.M., and Kinnison, M.T. 2014. Biomass 631 versus biodiversity: the relative contribution of population attributes to consumer nutrient 632 loading in aquatic systems. Evol. Ecol. Res. 16(8): 705-723.

633 Vanni, M. J. 2002. Nutrient cycling by animals in freshwater ecosystems. Ann. Rev. Ecol. Syst. 634 33:341-370. https://doi.org/10.1146/annurev.ecolsys.33.010802.150519

635 Vanni, M.J., and McIntyre, P.B. 2016. Predicting nutrient excretion of aquatic animals with 
metabolic ecology and ecological stoichiometry: a global synthesis. Ecology 97(12): 34603471. doi: 10.1002/ecy.1582.

638 Verdouw, H., Van Echteld, C.J.A., and Dekkers, E.M.J. 1978. Ammonia determination based on 639 indophenol formation with sodium salicylate. Water Res. 12(6): 399-402. doi: 10.1016/0043-1354(78)90107-0.

641 Villéger, S., Grenouillet, G., Suc, V., and Brosse, S. 2012. Intra- and interspecific differences in 642 nutrient recycling by European freshwater fish. Freshwater Biol. 57(11): 2330-2341. doi: $643 \quad 10.1111 /$ fwb.12009.

644 Wheeler, K., Miller, S.W., and Crowl, T.A. 2015. Migratory fish excretion as a nutrient subsidy 645 to recipient stream ecosystems. Freshwater Biol. 60(3): 537-550. doi: 10.1111/fwb.12495.

646 Whiles, M.R., Huryn, A.D., Taylor, B.W., and Reeve, J.D. 2009. Influence of handling stress and 647 fasting on estimates of ammonium excretion by tadpoles and fish: recommendations for 648 designing excretion experiments. Limnol. Oceanogr. Methods 7(1): 1-7. doi:

$649 \quad$ 10.4319/lom.2009.7.1.

650 Wood, J.L.A., Belmar-Lucero, S., Hutchings, J.A., and Fraser, D.J. 2014. Relationship of habitat 651 variability to population size in a stream fish. Ecol. Appl. 24(5): 1085-1100. doi:

$652 \quad 10.1890 / 13-1647.1$.

653 Wood, J.L.A., Tezel, D., Joyal, D., and Fraser, D.J. 2015. Population size is weakly related to 654 quantitative genetic variation and trait differentiation in a stream fish. Evolution 69(9): 655 2303-2318. doi: 10.1111/evo.12733. 
656 Table 1: Mean, minimum, and maximum sizes (g) of adult fish under laboratory conditions

657 (age 1.5) and in the wild (age 1+ and older).

\begin{tabular}{lllll}
\hline Population & Environment & Minimum & Maximum & Mean \\
\hline FW & Laboratory & 17.6 & 42.0 & 26.8 \\
FW & Wild & 3.0 & 47.8 & 8.1 \\
CC & Laboratory & 19.1 & 54.1 & 32.7 \\
CC & Wild & 2.4 & 51.6 & 16.7 \\
& & & &
\end{tabular}

658

659 
660 Table 2: Test statistics for terms modelling excretion rate $\left(\mu \mathrm{g} \mathrm{h}^{-1}\right)$ in two brook trout

661 populations for juveniles and adults, with retained terms bolded.

\begin{tabular}{lllll}
\hline Age & Parameter & Df & $F$ value & $P$-value \\
\hline Juveniles & Population & $1,9.79$ & 2.191 & 0.170 \\
& Mass & $1,23.24$ & 0.664 & 0.424 \\
& Population $x$ Mass & $1,28.23$ & 0.202 & 0.656 \\
Adults & Population & $1,32.38$ & 85.369 & $<\mathbf{0 . 0 0 1}$ \\
& Mass & $1,11.15$ & 18.459 & $\mathbf{0 . 0 0 1}$ \\
& Population $x$ Mass & $1,31.73$ & 0.176 & 0.677
\end{tabular}


663 Table 3: Test statistics for terms modelling specific growth rate over time in two brook 664 trout populations.

\begin{tabular}{llll}
\hline Parameter & df & $F$ value & $P$-value \\
\hline Population & $1,11.6$ & 6.129 & $\mathbf{0 . 0 3 0}$ \\
Time & $1,136.4$ & 4834.190 & $<\mathbf{0 . 0 0 1}$ \\
Population $x$ Time & $1,136.0$ & 0.475 & 0.492 \\
\hline
\end{tabular}

665

666 


\section{List of Figures}

668 Fig. 1. Allometric correlation between body mass (mass of individual fish, g) and excretion rate $669\left(\mu \mathrm{g} \mathrm{h}^{-1}\right)$ in two brook trout populations from Cape Race (CR) NL Canada (Cripple Cove River 670 (CC) = circles and dotted line; Freshwater River $(F W)=$ triangles and dashed line) for a) $0.5 \mathrm{y}$ 671 juvenile fish and b) $1.5 \mathrm{y}$ adult fish.

672

673 Fig. 2. Mean population excretion rates of adult fish from two brook trout populations (mean \pm

674 standard error), CC and FW from CR NL Canada: a) mass-specific excretion rate at $29.6 \mathrm{~g}$ for

675 both FW and CC adult fish, which is the average size of adult fish across both FW and CC

676 populations; b) absolute excretion rate for each population at its population-specific average size:

$67726.8 \mathrm{~g}$ for FW adults and $32.7 \mathrm{~g}$ for CC adults. CC trout are represented by circle symbols and 678 FW trout are represented by triangle symbols.

679

680 Fig. 3. Predicted whole population-level contribution of nitrogen from excretion to source

681 streams for adult brook trout collected from CC (grey symbols) and FW (black symbols) at Cape

682 Race, NL Canada between 2011 and 2014. Population-level total nitrogen excretion is expressed 683 as the total amount of nitrogen excreted per $\mathrm{m}^{2}$ of stream per unit of time: $\left(\mu \mathrm{g}\left(\mathrm{m}^{2}\right)^{-1}(\mathrm{~h})^{-1}\right)$, after 684 accounting for stream-area and body-size distributions of the two populations in the wild. Circles 685 represent excretion estimates using mean abundance estimates, and triangles represent lower and 686 upper 95\% confidence interval abundance estimates. 


\section{Appendix}

691 Appendix A. Methods for characterising physico-chemical conditions of FW and CC streams, 692 and lab-rearing of brook trout. 

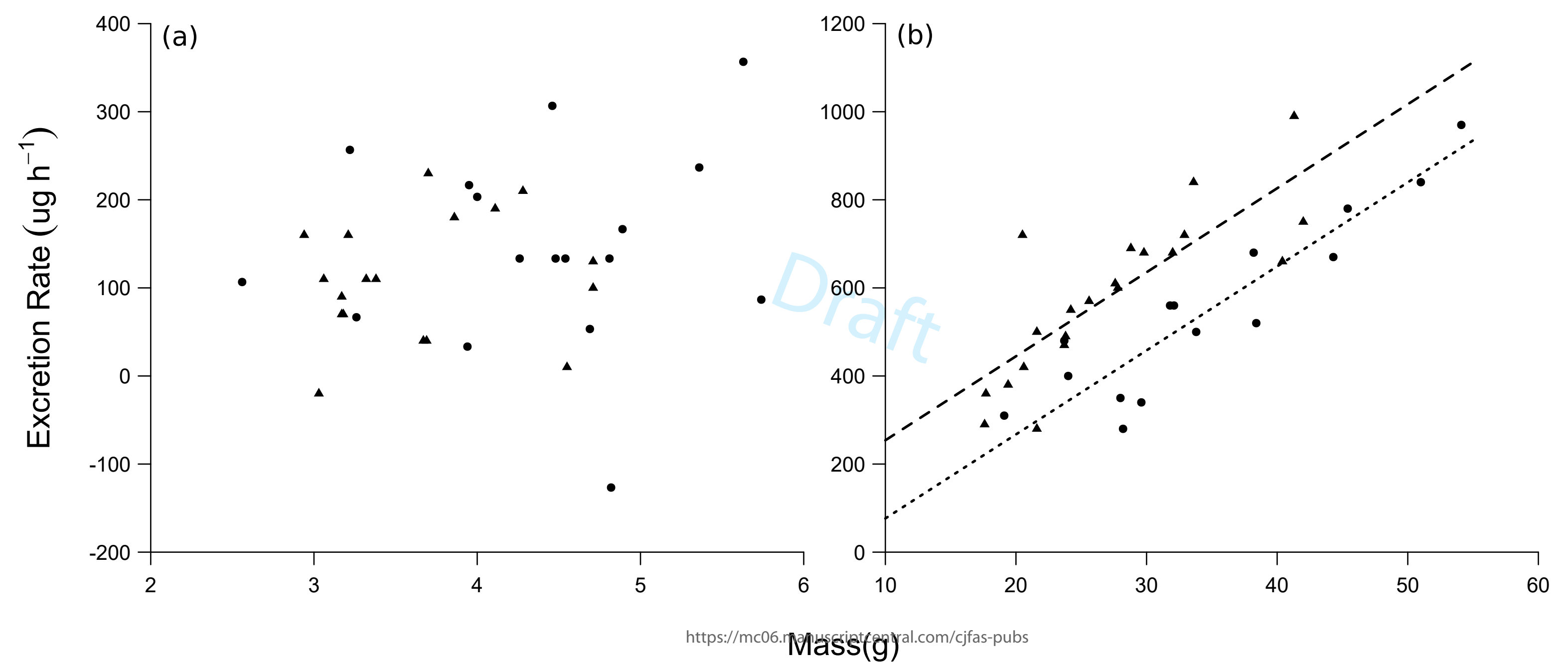
Page 3 7 andia) Journal of Fisheries andbAquatic Sciences

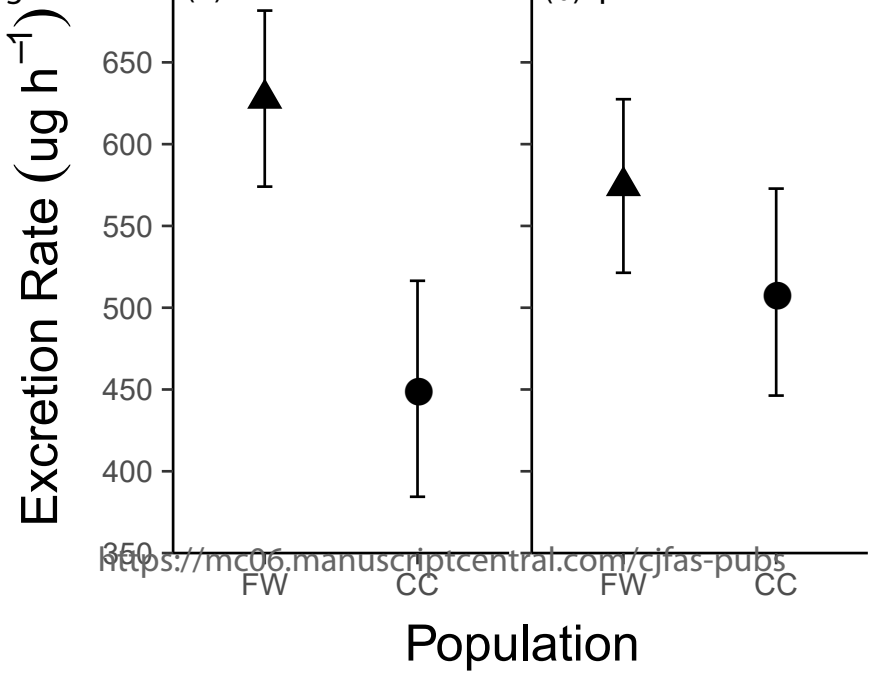




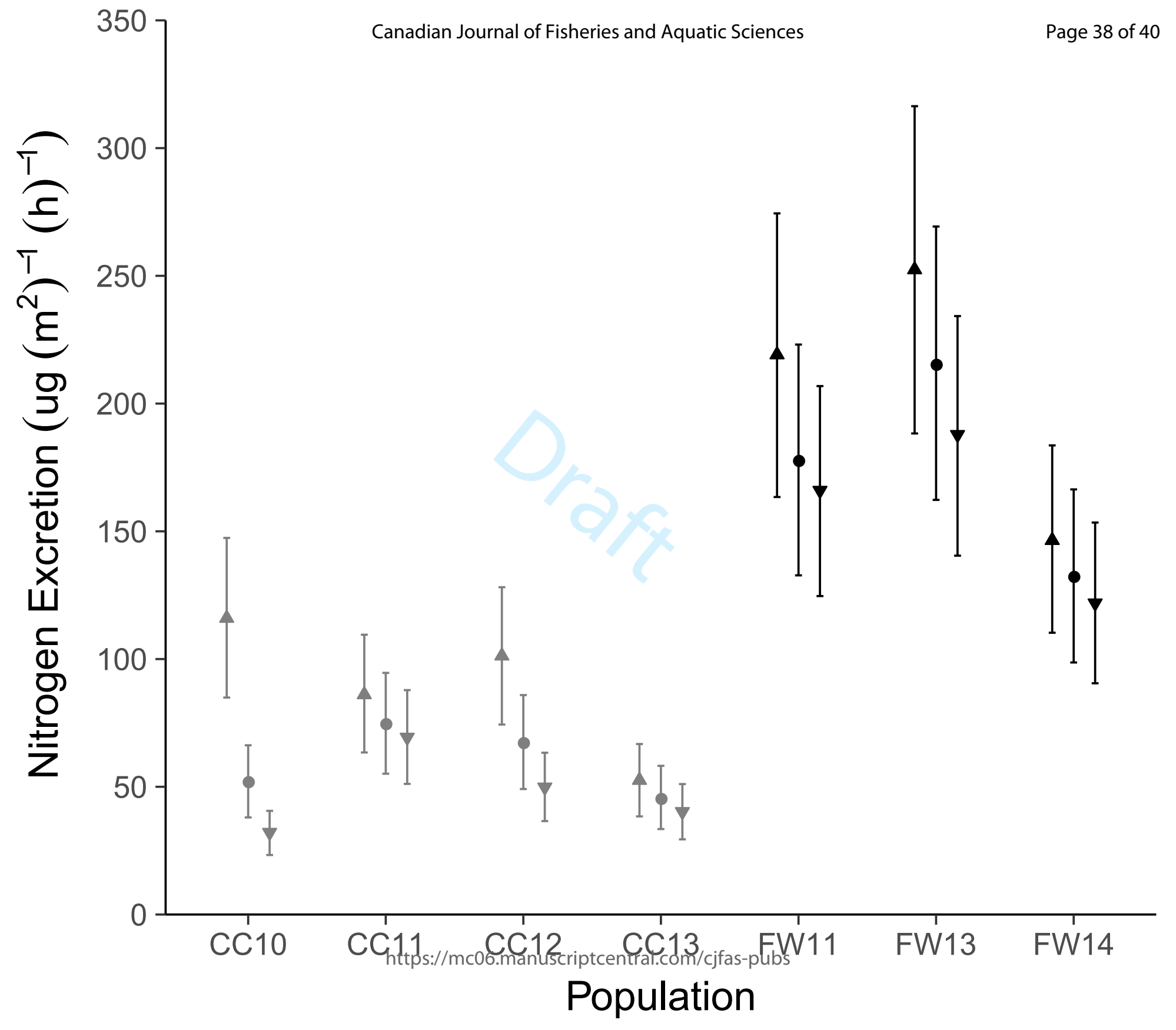




\section{Appendix A - Methods}

\section{Field - Physico-chemical and habitat characteristics of brook trout source streams}

For temperature $\left(\mathrm{Temp} ;{ }^{\circ} \mathrm{C}\right)$, values were calculated from readings measured continuously (every 01h30min) between late June 2015 and early September in $2015(\mathrm{n}=511)$ in each of Cripple Cove River and Freshwater River. One temperature data logger was placed at the center of each stream from late June to early September 2015 to capture seasonal variation in the temperatures to which brook trout are naturally exposed over the duration of the pond experiment. $\mathrm{pH}$, depth $(\mathrm{cm})$ and specific conductivity $\left(\mathrm{SPC} ; \mu \mathrm{S} \mathrm{cm}^{-1}\right)$ were measured during the month of June 2015 (Cripple $n=35$; Freshwater $n=61$ ). Dissolved oxygen $\left(D O ; \mathrm{m} \mathrm{L}^{-1}\right.$ ) was only measured in Freshwater river during the month of June 2015 (Freshwater n=13). Vegetation of stream bed covered (Veg; \%) and silt (Silt; \%) were also measured for each river habitat. N.D. indicates were no data were collected. $\mathrm{pH}$ and dissolved oxygen were measured between $15-19$ June 2015 along 34 transects in CC River (between $46^{\circ} 38.854^{\prime} \mathrm{N}, 53^{\circ} 06.269^{\prime} \mathrm{W}$ and $46^{\circ}$ $39.733^{\prime} \mathrm{N}, 53^{\circ} 06.756^{\prime} \mathrm{W}$ ) and along 61 transects in FW River (between $46^{\circ} 38.914^{\prime} \mathrm{N}, 53^{\circ}$ 13.301' $\mathrm{W}$ and $\left.46^{\circ} 40.128^{\prime} \mathrm{N}, 53^{\circ} 12.437^{\prime} \mathrm{W}\right)$.

\section{Lab - Fish Rearing and Maintenance}

Brook trout gametes were collected in October 2014 from electrofished CC and FW adults, transported during the night to Montreal QC, and used to generate family crosses (one different female $\times$ one different male) at Concordia University. Families were incubated in separate tubes within the same $1000 \mathrm{~L}$ recirculating tank at a controlled temperature of $7^{\circ} \mathrm{C}( \pm$ 0.2). After hatching and yolk absorption, alevins from each family were transferred at the same density to separate $10 \mathrm{~L}$ tanks for six months; fish were transferred again to larger $(2200 \mathrm{~L})$ tanks 
from six months to $1.5 \mathrm{y}$ of age and also maintained at the same densities. During these eighteen months, temperatures fluctuated seasonally as they do in nature $\left(3-19^{\circ} \mathrm{C}\right)$ within tanks whilst minimizing among tank differences $\left( \pm 0.2^{\circ} \mathrm{C}\right)$. Dissolved oxygen and $\mathrm{pH}$ were also kept the same across tanks (11.75 $\pm 0.15 \mathrm{mg} \mathrm{L}^{-1}$ standard deviation and $8.09 \pm 0.030 \mathrm{mg} \mathrm{L}^{-1}$, respectively). Fish were fed multiple times daily ad libatum with a mix of live Artemia salina (Linnaeus 1758) and aquaculture feed until six months of age, and once daily ad libatum on aquaculture feed only from six months to $1.5 \mathrm{y}$.

Within these populations, juvenile growth rate and adult body size are more variable in CC than in FW in the wild (Hutchings 1996). Fish were fed standardized quantities of live feed depending on tank density. Higher variation in the Cripple Cove population was likely a result of aggression, coupled with greater intrinsic growth rate. Fish densities were standardized across tanks and populations. 